\title{
China buys US sequencing firm
}

\section{BGI's rescue of Complete Genomics will keep a valued technology afloat.}

\section{BY MONYA BAKER}

ince it started sequencing genomes

$O$ in in 2009, the DNA services company

Complete Genomics has garnered praise for its technology, but little commercial success. Researchers valued its ability to produce readouts of entire human genomes with minimal errors, but they feared for the future of the company, based in Mountain View, California, which lost US\$72.3 million in 2011 alone. Now BGI, whose sequencing facility in Shenzhen, China, is the largest in the world, has tossed Complete Genomics a lifeline.

On 17 September, BGI announced that it had agreed to merge with the struggling firm and would spend $\$ 117.6$ million to buy up its shares. The rescue was welcomed not just by the company's board of directors, but also by those who worry that diminishing choices is a problem for genomics.

"Right now, Illumina would have a monopoly

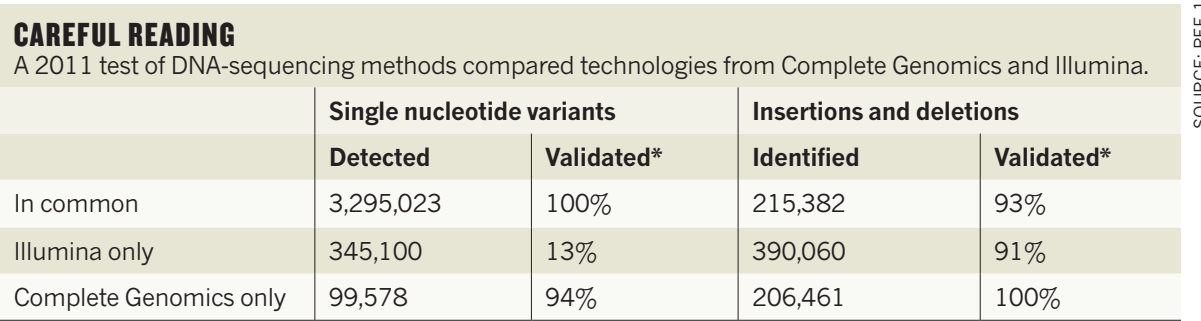

* A small, random sample of variants was reanalysed by a more accurate but more expensive method.

if Complete Genomics went under," says Michael Snyder, director of the Stanford Center for Genomics and Personalized Medicine in Palo Alto, California. Instruments made by Illumina of San Diego, California, account for most of the world's sequencing output. Maintaining competition in the industry will keep prices low and technologies improving, Snyder says.

Like Complete Genomics, BGI sells sequencing services rather than equipment or reagents, but it relies chiefly on instruments made by
Illumina. Complete Genomics has its own instrument and software platform, which is specialized for sequencing whole human genomes.

Although comparing ever-changing platforms is never straightforward, a 2011 analysis of the same genome read by Complete Genomics and Illumina technology showed that although the former found fewer variants in the DNA sequence relative to a standard reference, it was more accurate (see 'Careful reading' $)^{1}$. In July, Complete Genomics 
- described a technique that reduces error rates in sequenced genomes to 1 in 10 million base pairs and shrinks the amount of DNA required to generate a sequence ${ }^{2}$. The technique also distinguishes between DNA fragments that come from paternal and maternal versions of the same chromosome. This can reveal, for example, whether mutations occur in one or both copies of a gene, and so whether an individual is at risk of developing a certain disease or is merely a carrier.

"That's going to be a game changer in how whole-genome sequences are interpreted and analysed," predicts Thomas Barber, a geneticist at Eli Lilly in Indianapolis, Indiana, who works with both BGI and Complete Genomics. BGI's acquisition means that researchers will continue to benefit from such advances. Having the two companies under the same ownership could combine the strengths of both.

Amanda Murphy, an analyst with equity investment firm William Blair in Chicago, Illinois, says that the market for Complete Genomics' expertise is poised to grow. Most human sequencing has so far focused on exomes, the roughly $1.5 \%$ of the genome that codes for protein. But the recent ENCODE project $^{3}$ and other research is revealing functions of non-protein-coding regions. "I think the world is moving towards whole-genome sequencing," she says. "The demand just wasn't there fast enough" for Complete Genomics to hang in on its own.

Demand for services is increasing as well. Many researchers want to use sequencing data but do not want to invest in the expertise and instruments needed to do the sequencing themselves. Even large academic sequencing centres often have more sequencing projects than capacity.

A major drawback of Complete Genomics' technology is that it takes 2 to 3 months to produce a sequence, which discourages medical uses. But the platform is expected to get faster. Peter van der Spek, head of bioinformatics at Erasmus Medical Center in Rotterdam, the Netherlands, worries that innovation will stall under BGI, although a spokesman for BGI says that Complete Genomics' current scientific staff is expected to stay with the company and that development would continue.

Either way, the community is better off with options, says Richard Gibbs, director of the Human Genome Sequencing Center at Baylor College of Medicine in Houston, Texas. "If we just had one test and one machine and one process, things would happen, but not as fast." -

1. Lam, H. Y. K. et al. Nature Biotechnol. 30, 78-82 (2011).

2. Peters, B. A. et al. Nature $487,190-195$ (2012).

3. The ENCODE Project Consortium Nature 489, 57-74 (2012).
PUBLISHING

\section{Open-access deal for particle physics}

Consortium brokers agreement with 12 journals.

\section{BY RICHARD VAN NOORDEN}

$\mathrm{T}$ The entire field of particle physics is set to switch to open-access publishing, a milestone in the push to make research results freely available to readers.

Particle physics is already a paragon of openness, with most papers posted on the preprint server arXiv. But peer-reviewed versions are still published in subscription journals, and publishers and research consortia at facilities such as the Large Hadron Collider (LHC) have previously had to strike piecemeal deals to free

After six years of negotiation, the Sponsoring Consortium for Open Access Publishing in Particle Physics $\left(\mathrm{SCOAP}^{3}\right)$ is now close to ensuring that nearly all particle-physics articles - about 7,000 publications last year - are made immediately free on journal websites. Upfront payments from libraries will fund the access.

So that individual research groups do not need to arrange open publication of their work, the consortium has negotiated contracts with 12 journals that would make $90 \%$ of highenergy-physics papers published from 2014 onwards free to read, says Salvatore Mele, who leads the project from CERN, Europe's high-energy physics laboratory near Geneva, Switzerland, and home of the LHC. According to details announced on 21 September, six of the journals will switch their business models entirely from subscription to open access. It is "the most systematic attempt to convert all the journals in a given field to open access", says Peter Suber, a philosopher at Earlham College in Richmond, Indiana, and a proponent of open access.

The consortium invited journals to bid for three-year open-access publishing contracts, and ranked them by an undisclosed algorithm that weighed their fees against their impact factors and the licences and delivery formats they offer. Under the deal, the journals will receive an average of $€ 1,200$ (US $\$ 1,550$ ) per paper. Physical Review D, the journal that publishes most papers in the field, negotiated a fee of US $\$ 1,900$ per article "on the principle that we should maintain our revenue", says Joe Serene, treasurer and publisher at the American Physical Society, which owns the journal. But the society's $\rightarrow$ NATURE.COM For a complete list of participating journals see. go.nature.com/3yvpzq up a few hundred articles.

prestigious Physical Review Letters missed out because its bid was too high, says Serene (the journal currently charges authors $\$ 2,700$ for individual open-access articles). CERN and SCOAP $^{3}$ will continue to negotiate individual open-access agreements with journals not included in the deal, and more could join when the contract is renegotiated in 2016.

Mele says that the goal of $\operatorname{SCOAP}^{3}$ is to switch the discipline's journals to open access without researchers noticing any effect on their grant funding or on the way they publish papers. The consortium will pay the contracts from an annual budget of $€ 10$ million, which is funded not by authors or research grants, but by pledges from more than a thousand librar-
"It is the most systematic attempt to convert all the journals in a given field to open access." ies, funding agencies and research consortia across the world. In effect, existing journal subscription fees are being repurposed to provide the open-access funds.

Before any contracts can be signed, however, publishers must reduce the price of their subscription packages to offset the income from $\mathrm{SCOAP}^{3}$ - a complex calculation to ensure that libraries don't pay twice for the same content. Then $\mathrm{SCOAP}^{3}$ must collect its pledges - not a foregone conclusion, as some libraries may be tempted to renege, figuring that their institution won't lose access to the free papers anyway.

Mele hopes that success could trigger a domino effect in fields such as astronomy and astrophysics. "I personally believe that once this is demonstrated to work, some variations, fine-tuning and adaptation of the idea will emerge," he says.

But Serene and others caution that $\mathrm{SCOAP}^{3}$ may be hard to replicate. It has unique advantages in that most high-energy-physics papers are published in just a few journals, and that the field can be driven and coordinated by one central organization, CERN.

Suber notes the stark contrast between the quiet brokering of $\mathrm{SCOAP}^{3}$ and the battles playing out over mandates for open-access publication by research funders such as foundations and government agencies (see Nature 486, 302-303; 2012). "I call it the peaceful revolution," he says. 